\title{
Multiculturalismo e as Relações Hibridas na Educação
}

\author{
Multiculturalismo e as Relações Hibridas na Educação \\ Multiculturalism and Hybrid Relationships in Education
}

\author{
Shirlei Alexandra Fetter ${ }^{1}$ \\ Daniel Luciano Gevehr ${ }^{2}$
}

\begin{abstract}
Resumo
Este estudo buscou ressaltar as concepções de hibridismo cultural. A discussão se expõe com fundamentos sobre como se caracteriza hibridismo cultural, interculturalismo e multiculturalismo, bem como sua representação na sociedade contemporânea. No decorrer, o texto centraliza à cultura ao analisar as práticas educativas desenvolvidas na contemporaneidade. Elas chamam a atenção para a ressignificação do currículo como espaço interativo sobre as identidades homogêneas. Nesse contexto, as discussões permeiam sobre as propostas curriculares sob uma abordagem hibrida. Destarte, entendemos que o mais importante ao se discutir a centralidade da cultura nas abordagens curriculares não é o intercultural ou multicultural, mas a concepção de que a cultura, conforme o modelo de hibridismo que apresenta a diversidade cultural que é a da multiculturalidade existente em diversos grupos culturais de uma mesma sociedade.
\end{abstract}

Palavras-Chave: Culturas, Diálogos, Formação, Multicultura, Relações.

\section{Resumen}

Este estudio trata de poner de relieve las concepciones hibridación cultural. La discusión se establece causas se caracteriza en la hibridación cultural y el multiculturalismo y su representación en la sociedad contemporánea. En todo momento, el texto se centra en la cultura para analizar las prácticas educativas desarrolladas en la época contemporánea. Lo llaman la atención sobre la redefinición del plan de estudios como un espacio interactivo sobre las identidades homogéneas. En este contexto, las discusiones sobre impregnan las propuestas curriculares bajo un enfoque híbrido. Por lo tanto, entendemos que lo más importante cuando se habla de la centralidad de la cultura en los enfoques curriculares no es el intercultural y multicultural, pero el diseño de esa cultura, como modelo híbrido que muestra la diversidad cultural que es el multiculturalismo que existen en varios grupos culturales dentro de la misma sociedad.

Palabras claves: Culturas, el diálogo, la formación, Multicultural, Relaciones.

\section{Abstract}

This study sought to highlight the conceptions of cultural hybridity. The discussion is based on how cultural hybridism, interculturalism and multiculturalism are characterized, as well as their representation in contemporary society. In the course, the text centralizes to the culture when analyzing the educative practices developed in the contemporaneity. They call attention to the re-signification of the curriculum as an interactive space on homogeneous identities. In this context, the discussions permeate the curricular proposals under a hybrid approach. Thus, we understand that what is most important when discussing the centrality of culture in curricular approaches is not intercultural or multicultural, but the conception that culture, according to the

\footnotetext{
${ }^{1}$ Mestranda pelo Programa de Pós-Graduação em Desenvolvimento Regional (PPGDR) - Bolsista Capes; Faculdades Integradas de Taquara - FACCAT; Taquara, Rio Grande do Sul, Brasil; fettershirlei@ gmail.com.

${ }^{2}$ Doutor em História e professor do Programa de Pós-Graduação em Desenvolvimento Regional (PPGDR); Faculdades Integradas de Taquara - FACCAT; Taquara, Rio Grande do Sul, Brasil; danielgevehr@ hotmail.com. Trabalho apresentado no I Seminário Latino-Americano de Estudos em Cultura - SEMLACult, Foz do Iguaçu/PR, Brasil, 2017.
} 
model of hybridism that presents the cultural diversity that is the multiculturality existing in several Cultural groups of the same society.

Keywords: Cultures, Dialogue, Training, Multicultural, Relationships.

\section{Introdução}

As culturas contemporâneas se encontram incorporadas, dialogando entre si e, para os estudiosos sobre o assunto, têm se tornado semelhante, recebendo assim, uma nova terminologia - culturas - não sendo mais possível referir-se a elas como uma coisa que se unifique. Este elemento foi possibilitado pelo acréscimo do segmento globalizado que promoveu o encurtamento das distâncias e a propagação - nível mundial gradativo - da exposição dos meios de comunicação, enquanto principais responsáveis por ligarem pessoas das mais diversas partes do mundo. Mas o fato é que essa homogeneização é propiciada, principalmente - pela padronização do consumo e por consequência - a dominação da cultura Norte Americana como modelo de vida (MOSCOVICI, 2010).

Canclini (2013) busca observar o hibridismo - através de aspectos assertivos que se fundamentam - sobretudo, o multiculturalismo como um espaço que promove o diálogo entre as culturas, um elemento novo que resulta do encontro entre as culturas diferentes. $\mathrm{O}$ hibridismo visto sob a ótica do autor, penetra entre os espaços como uma espécie de tolerância às diferenças culturais. No entanto, a apresentação do pensamento do autor e as contribuições são trazidas para entender esse processo.

Outrossim, a diversidade cultural apresenta vários aspectos que representa particularmente - a diferenças entre as culturas, caracterizando-as como a linguagem, as tradições, a culinária, a religião, os costumes, o modelo de organização familiar, a política. As múltiplas culturas formam a chamada identidade cultural dos indivíduos ou de uma sociedade - uma característica - que personaliza e diferencia os membros de determinado lugar do restante da população mundial. Consequentemente, o hibridismo decorre como um processo multicultural, de diálogo entre as diversas culturas (CANCLINI, 2013).

Evidenciam-se os sentidos que se atribuem às construções de conhecimentos contemporâneos. Entende-se que este processo é composto não só por teoria e prática, mas pela transposição em que as culturas dos povos se entrecruzam, isto é, processos socioculturais de relação e inter-relação de conhecimentos, valores e saberes tradicionais (CANCLINI, 2013). Nesse sentido, faz-se uma reflexão sobre os diversos significados atribuídos ao multiculturalismo - através das práticas curriculares que ainda hoje continuam 
reproduzindo as estruturas homogêneas de poder e de hierarquização cultural - repensando as práticas pedagógicas dominantes (NEGRI, 2010).

Busca-se dar espaço e oportunidades, ao caráter daquilo que se possui como dois aspectos radicalmente diferentes. São possibilidades, que buscamos a compreender através do conceito de hibridismo - o que procuramos fazer - no presente estudo, a partir do entendimento de seu formato e identidade na contemporaneidade. Conforme Dussel (2002) de certa forma as características permitem a sua integração - através do qual - possibilite questionamentos entre as relações de poder estabelecida na sociedade atual, as quis perpassam a barreiras entre educação e o currículo.

\section{Processo de Hibridação Multicultural}

Observamos o hibridismo através de um aspecto positivo fundamentado, principalmente, no multiculturalismo como dimensão que integra e proporciona o diálogo entre as culturas impares. Podemos dizer que o hibridismo - abre espaço também a uma espécie de tolerância às diferenças culturais - traçando o viés cultura à multiculturalidade pelo encontro entre as diferenças. Assim dissemos, que as trocas e as interações - entre sociedades - coincidem com o início da história da humanidade, ou seja, sempre ocorreu o contato entre diferentes culturas (CANCLINI, 2013).

Em consequência disso, a diversidade cultural apresenta-se como tema de interesse aos pesquisadores nas áreas sociais - a partir do processo de descolonização ocorrido na América Latina - e consequentemente pelo fluxo de emigrantes. Por estas razões o movimento migratório - que alcançou seu ápice nos anos setenta e oitenta - provoca transformação nas sociedades tendo como inferência o aparecimento de situações excludentes e falta de tolerância à convivência com o "outro". Neste sentido, o diferente agora frequenta as "ruas e praças, mercados e igrejas, escolas e cinemas" - busca por uma vaga de emprego - trazendo em sua bagagem cultural valores que colocam em cheque as tradições morais das instituições (MOURA, 2005).

Kramsch (2013), por sua vez, sustenta o conceito de interculturalidade, usando-o para indicar um conjunto de propósitos e de convivências respeitosas - entre diferentes culturas integrando entre elas a diversidade. $O$ termo tem origem e vem sendo utilizado com frequência nas teorias e ações pedagógicas, mas ampliou o contexto educacional e ganhou maior amplitude passando a referir-se também às praticas culturais (CANDAU, 2010).

Ao fazer uma análise da sociedade Canclini (2013) enfatiza a multiculturalidade em relação a interculturalidade, isto é, caminha em direção ao conhecimento e à compreensão 
das diferentes culturas. Dada esta tendência, a diversidade cultural, ocasiona a intercultura - a qual significa diversidade de culturas - assim como o respeito e a compreensão aos diferentes. Definitivamente o discurso sobre a interculturalidade se apoia na necessidade do diálogo das múltiplas culturas.

Novos conhecimentos entre novas culturas são a possibilidade de construção de culturas que se cruzam a partir do diálogo ou mesmo do conflito, já que uma das marcas da cultura e a pluralidade e diversidade enaltecida no interior de cada uma delas. Ao referir-se sobre o interculturalismo, Canclini (2013) incorpora o movimento multicultural sobre os aspectos das lutas, diálogo e a comunicação, isso resultando em identidades híbridas. Por essas razões alerta sobre conceitos que costumam se confundir em diferença e desigualdade. Apesar de estarem, na maioria das vezes, intrinsecamente relacionados.

Em síntese, os estudos mencionados implicam em desafios - das apropriações teóricas do multiculturalismo na educação - quanto do proposito pedagógico-curriculares que examinam e proporcionam às vozes excluídas. Desafio sugerido, que abarca as relações entre currículo e multiculturalismo, pode ser ilustrado com Moreira (2000) como aproximação com autores que discutem e abordam as questões múltiplas. Igualmente, o currículo como um espaço de reinvenção sobre a pluralidade que modelam as características identitárias.

Sobre essas concepções, associa-se à recontextualização que se caracteriza pelas mudanças nas regras discursivas na passagem de um contexto para outro. Tais mudanças não acontecem pelas regras de classificatórias e de enquadramento - que possui a capacidade e o controle em que se expressam - ou pelo menos não apenas por situarem-se ao meio delas, mas também pelos hibridismos. Canclini (2013) considera essa expressão como negativa e sintetiza a relação que faz a teoria crítica da hibridização, mas o entendimento com o processo de hibridização, identificando-o sobre o que não aceita e o que não pode ser hibridizado.

Bhabha (2001) apresenta o conceito híbrido como um termo dialético expresso entre culturas que busquem reconhecer o individua pertencente a uma sociedade multicultural. Constituir as características pela perspectiva do reconhecimento - são processos necessários aos exercícios do reconhecimento - própria à dinâmica dos sentidos e dos significados. Afirma Hall, (2001) que o sujeito se constitui pela sua essência de interna - formado e modificado - na continuidade do dialogo contínuo com os processos culturais exteriores.

Transpondo-nos aos escritos sobre as políticas de currículo e suas discussões sobre as múltiplas culturas no espaço educacional. As situações de multiplicidade tornam ainda mais as relações favorecidas no sentido investigativo das politicas curriculares e seus entendimentos sobre as prioridades - com isso, as ações curriculares envolvem a realidade 
global/local - Ball (1998) distingue esse procedimento que se constitui pelas ações políticas que hibridizadas pelas lógicas globais, propõe uma relação interativa entre o nacional e o global na política educacional.

\subsection{As relações inter, multi e hibridas na educação}

Este estudo sobre o inter e multiplo são temas conectos, elogiável ao currículo escolar. Na educação, são assuntos que não só estão comprometidos uns com os outros - muitas vezes - manifestam-se juntas. É inviabilizada a abordagem multicultural nos currículo sem problematizar as múltiplas relações na escola. Segundo Gonçalves e Silva (1998, p. 33), “o multiculturalismo não interessa à sociedade como um todo, e sim a certos grupos sociais e culturais". Nessa perspectiva, as reflexões sobre as identidades culturais - chamadas de novos sujeitos - exige empenho e repensar afim de novos sentidos ao que se estipulou considerar como relações híbridas na educação.

Para além das questões levantadas, pode-se refletir sobre os efeitos que a educação fragmentada e descontextualizada pode ter para os estudos e também, numa perspectiva mais ampla, para a sociedade. Bourdieu (1989) atesta que, a deficiência no processo de formação impede a compreensão da realidade social, ao mesmo tempo em que inviabiliza a constituição de vínculos solidários de segmentos que poderiam organizar-se na luta contra o capital.

Nessa continuidade, a subdivisão das lutas em torno de identidades multiculturais ou das questões regionais desvinculadas em especifico o poder de pressão que favorece a hegemonia burguesa. Portanto, é dentro deste cenário histórico que devemos buscar a compreensão das propostas hegemônicas presentes na educação escolar, que contribuem para a fragmentação dos conteúdos, com um notório esvaziamento do trabalho pedagógico e precarização da formação docente (GOMES e COLARES, 2012).

Gramsci (1978) apresenta uma concepção de hegemonia mais elaborada e adequada em pensar sobre as relações sociais, sem cair no materialismo vulgar e no idealismo. A noção de hegemonia propõe uma nova relação entre estrutura tentando se distanciar das determinações da primeira sobre a segunda, mostrando a centralidade das superestruturas na análise das sociedades avançadas. Nesse contexto, a sociedade civil adquire um papel central, bem como a ideologia, que aparece como constitutiva das relações sociais.

O conceito de hibridismo permite interpretar por novas perspectivas de análise a compreensão dos processos de reconhecimento, de legitimação, de interpretação e de apropriação sobre as políticas curriculares nas exigências que transitam até à sua efetiva implementação no campo prático. O processo de hibridação implica em criar espaços de 
exploração e compreensão das possibilidades que se manifestam através da cultura e da história. É nesse espaço que acontece a negociação de sentidos e de significados entre visões de mundo diferentes, fazendo surgir novas compreensões sobre a realidade, além de administrar a diversidade, que é uma necessidade na interpretação de uma cultura cívica democrática.

Dessa forma, ao vivenciarmos um momento histórico de predominância de um projeto que representa um retrocesso em termos de responsabilidade com a educação pública, é preciso afirmar a educação híbrida e libertado para lutar contra as intenções do estado que pretende esvaziar o papel da educação escolar (GOMES e COLARES, 2012). É preciso afirmar a ideia de que a educação é um direito social de todos, e combater a ideia cada vez mais difundida de que a educação é um serviço, que vai ser prestado se adquirido no mercado.

Mais do que nunca, no atual contexto de globalização das tecnologias de informação e comunicação às sociedades modernas defrontam-se com realidades híbridas que resultam da interação e divulgação de saberes, conhecimentos e práticas culturais diversas. É um momento que, se bem orientado, pode favorecer a formação de conhecimentos mais efetivos e humanos.

O discurso híbrido, apontado por Canclini (2013), reivindica a noção de colaboração de saberes, indo, portanto, contra as noções tradicionais de razão, verdade, objetividade. Questiona, dessa forma, os conceitos de desenvolvimento, emancipação e as grandes narrativas, implicando em multiplicação no âmbito de formação acadêmica. O processo de formação para melhor atender os anseios de uma formação híbrida, exige um trabalho de formação a ser fundamentada por uma pedagogia adequada (RAYNAUT, 2014). Esse processo busca entender a produção do conhecimento como imprescindível na formação de profissionais da educação, com sentido mais amplo, repensando a relação entre o ensino e pesquisa.

\subsection{Hibridismo e currículo: características opostas no contexto educacional}

O hibridismo tem estado no foco de estudo de muitos autores, constituindo-se em componente fundamental da análise dos processos de produção de políticas e de práticas curriculares em diferentes contextos educacionais. Seu conceito apresenta tendências hibridas - de distintas teorias, as quais consideram a categoria do campo curricular na contemporaneidade. Sob essa análise, Lopes e Macedo (2002) configuram o campo curricular destinado à diversidade no Brasil. 
Às teorizações de caráter globalizante, que abrangem a multiplicidade enquanto característica da contemporaneidade. São propensões e capacidades que se inter-relacionam, produzido pelos processos culturais. Idealizada por Canclini (2013) as culturas híbridas foram proposta - no início da década de 90 - com o intuito de refletir sobre a modernidade latinoamericana, a qual havia apresentado uma modernidade, identificada pelo conjunto de culturas, pelo crescimento dos meios desenvolvidos e pela diversificação (DUSSEL, 2002).

Atribuir a importância as práticas culturais, políticas e sociais em que o hibridismo se inscreve. Focaliza-se as intenções teóricas com Dussel (2002) sob o ponto de analisar o currículo - em termos híbridos que o constitui - assim, proporcionar novas possibilidades de reflexão sobre os processos culturais, políticos e sociais que o representam. Em vista disso, as novas ideias advindas para o campo do entendimento, principalmente se considerar a memória do pensamento curricular - dedicado à ação técnica, procurando formas curriculares transparentes.

Conceituando hibridismo, permite-se interpretar por novas perspectivas de análise a compreensão dos processos de reconhecimento, ao quais estão de acordo, com as políticas curriculares nas diferentes iminências práticas. A educação, em diferentes épocas e contextos, direciona seu discurso pedagógico/curricular que, além de ir ao encontro dos princípios que antecedem as tradições e as experiências nacionais e locais. Nesse processo, a hibridação implica no conjunto de interpretações - que propõe novas experiências - e direções em relação com as que já estavam intrínsecos nos discursos híbridos, dando sentido e articulando sua constituição (DUSSEL, 2002).

Traduzir a diferença cultural é uma importante tarefa para o educador crítico (MCLAREN, 2000). As linguagens culturais são as especificidades contextuais dos sistemas educacionais. Na condição de formadores e transformadores, professores críticos assumem a responsabilidade de dialogar entre a diversidade cultural. As atividades práticas significativas se traduzem - não pelo vazio ideológico - realizando-se através do diálogo crítico e interrogativo proporcionado para produzir suas leituras interpretativas sobre as políticas e sobre as práticas curriculares.

As interpretações sobre o conceito cultural estão abertas à tradução justamente porque os significados culturais são híbridos. Os mesmos opõem-se as forças de totalização e isolamento completo, dentro dos discursos de autenticidade, raça, classe, gênero ou essências. Preciso ter consciência que as culturas não são identidades fechadas - que ficam estagnadas através dos tempos - são lugares de sentido e de controle, que se alteram e ampliam-se por 
conta de novas interações. É importante ressaltar, as considerações de Canclini (2013) que não é possível hibridizar qualquer contexto, estrutura ou objeto cultural.

Logo, não se põe em prática as atribuições de qualquer pertença às políticas ou exposições curriculares. Dar ênfase aos autores das políticas não quer dizer que o controle de todos os sentidos que serão interpretados, mas operam buscando superar os limites sobre as possíveis interpretações, tendo como verossímil aquela entendida como correta. Esse entendimento sobre à leitura, realiza-se não apenas com base no estímulo, mas nas necessidades de discursos que justifiquem e legitimem a proposta curricular a ser desenvolvida (BALL, 1998).

Por intermédio de instituições as condições - culturais - contextuais e históricas de produção e de leitura têm importância no conhecimento e na interpretação de sentidos e significados. Podem ser oferecidas, pelas instituições escolares, possibilidades ou limites à interpretação e ressignificação de contextos culturais. É destacável a percepção sobre esse processo sob a ótica Ball (1998), Lopes (2004) que analisam as tendências políticas de currículo por processos de recontextualização em diferentes instâncias - pelas quais transitam - desde o nível em que são produzidas até à instância da prática.

Por meio desse processo novos sentidos são produzidos e novas culturas podem emergir. O resultado decorre das mesclas hibridas, configuradas no interior desse espaço de recontextualização. Segue a importância do reconhecimento mencionado por Dussel (2002) quando argumenta que o conceito de hibridismo permite vislumbrar novas perspectivas sociais - enquanto processo de novas oportunidades - para que o currículo, considere os diferentes aspectos culturais e conceituais a que está sujeito.

E possível identificar exposição de culturas híbridas na educação desde as manifestações na escola pública. A própria ideia imediata e intuitiva de currículo pode ser considerada como um conceito híbrido, isto é, encontra resultado a partir de um processo que se multirelaciona e a cultura se traduz a um ambiente múltiplo, porém cada sujeito com sua subjetividade. Assim, os discursos curriculares são híbridos - pois distintas tradições e movimentos - se constituem e proporcionando espaço a determinados consensos (DUSSEL, 2002).

As produções culturais - nessas diferentes instâncias - apresentam características e influências recíprocas. Tais sentidos apresentam-se de certa forma com as políticas curriculares, as quais precisam ser interpretadas e relacionadas a realidade. Como destaque, Lopes (2004) apresenta os discursos sobre tecnologias que se desenvolvem em todo processo social da educação. São as diferentes culturas - as quais transitam os contextos - das 
instituições escolares e requerem definições e diretrizes curriculares, para assim serem interpretadas e reinterpretadas continuamente.

E na própria escola que se reconhece os processos de hibridação. Ao viés prático, as propostas curriculares podem apresentar uma diversidade de expressões culturais através de diferentes grupos disciplinares. As histórias, concepções e formas de organização - em que os grupos - identificam-se e reproduzem os sentidos de suas existências, são, por vezes, despercebidos das atividades propostas pela estrutura curricular que compõe a instituição escolar. Lopes (2004) analisa essa situação, e chama a atenção para as representações dos grupos interdisciplinares que compõe o contexto cultural da sala de aula no Brasil.

Percebe-se nesse processo sentido duplo. Lopes (2004) atenta para a interpretação dos contextos culturais de forma fragmentada e alguns desfeitos mais valorizados que outros, ou seja, os fragmentos têm como capacidade desenvolver-se - pela interdisciplinaridade - as relações hibrida transferência de um contexto a outro. Com isso, as diferenças entre há experiências nas escolas - buscando a integração e a mudança - podendo ou não favorecê-las, através dos compromissos e histórias que dizem respeito aos paradigmas pedagógicos e sua relação com os discursos, produzindo a hibridização e dando origem a novos sentidos que a sociedade contemporânea apresenta.

O hibridismo é inerente à recontextualização das propostas curriculares. Ao visarem o desenvolvimento e uma transformação social significativa, as políticas de currículo geram, por sua vez, híbridos culturais com novos conceitos ou novos sentidos para velhos conceitos (LOPES, 2004). Tomada a consciência desta realidade - motivada pelas relações sociais - os fatos que representam, não só na escola, mas em diferentes espaços, quer dizer, presentes no tecido social.

Referindo-se a realidade que desperta comportamentos e desenvolvimentos sociais. Valorizar essa mescla - hibrida - entre os sujeitos favorece a aprendizagem "formando um tecido colorido de conhecimento, cujos fios expressam diferentes possibilidades de interpretação e de entendimento de um grupo de pessoas" (MANTOAN, 2006, p. 52). A moralidade da formação multicultural - de uma sociedade - não leva espontânea e necessariamente ao desenvolvimento de uma dinâmica social, por si só, mas iniciada por práticas pedagógicas significativas. Entende-se o multiculturalismo como realidade social de caráter múltiplo e inter, ou seja, composta por diferentes grupos culturais numa mesma sociedade.

\section{Conclusões}


As questões multiculturais que se apresenta na sociedade e adquirem extensão que abrangem conjuntura marcada por rivalidades, incertezas e conflitos, tanto no âmbito internacional, como nacional e local. Consequentemente essas indecisões permeiam pela política, economia, arte, religião, tecnologia e educação. Se de um lado as tensões e os conflitos se multiplicam, de outro, as desigualdades sociais, as relações desarmônicas são realidades que não podem ser fragmentados das inquietudes multiculturais.

As certezas vão facultando lugar à desconstrução, pluralização, ressignificação, reinventando identidades, subjetividades, saberes, valores, convicções, horizontes de sentido. Somos convidados a assumir o múltiplo, o plural, o diferente, o híbrido. Não se trata de amplitude a dimensão cultural desvinculando-as, das questões de caráter problemático da desigualdade, nem tão pouco considerá-la um mero produto desta realidade. Trazendo à baila os conceitos de multiculturalismo, interculturalismo e hibridismo cultural, nos aproximamos de Canclini (2013) ao entender que o processo de hibridização como uma multicultura capaz de proporcionar o respeito, a valorização e a tolerância entre as diversas culturais que se entrecruzam.

Em resumo os processos de desterritorialização são responsáveis, pela expansão dos gêneros culturais que possibilitam a entrada e a saída da modernidade e que refletem o contexto de hibridismo cultural, ou seja, à quebra de divisões e no enaltecimento de narrativas híbridas. Deixamos como reflexão a perspectiva multicultural pela opção em organizar os conteúdos curriculares através dos temas geradores. Isso nos parece significativo, pois nos indica que uma política curricular pode ser multicultural sem, necessariamente, assumir os pressupostos teóricos.

Sobre tudo, as culturas contemporâneas se encontram mescladas, dialogam entre si. Este fator é influenciado pela intensificação do processo de globalização que proporcionou o encurtamento das distâncias e a sua propagação. Mas o fato é que essa homogeneização é possibilitada, principalmente porque entendemos que o hibridismo não possui, necessariamente, uma perspectiva ou um desdobramento de superação e libertação, ou seja, um desdobramento com garantia de final feliz, entretanto, que ele significa a existência de espaços onde as diversidades culturais podem tomar posições mais favoráveis nas reformas curriculares.

Enquanto entendimento dos aspectos culturais na contemporaneidade e dos processos políticos/sociais que se constituem, a compreensão sobre o conceito de hibridismo abre perspectivas de análise sobre a complexidade desses processos. O sentido amplo do conhecimento sobre os elementos de argumentos e resistências que possam direcionar senão à 
mudança social, pelo menos a reflexão crítica das relações, que engendram a injustiça, a desigualdade a dominação racial, cultural, econômica e política na nossa sociedade. Essa leitura crítica é fundamental para novas perspectivas de análise, de conhecimentos e de ideias que podem situar-se, assim como novos sentidos e significados apontados através da educação e o currículo.

\section{Referências}

BALL, S. Cidadania global, consumo e política educacional. In: SILVA, L. H. (Org.). A escola cidadã no contexto da globalização. Petrópolis: Vozes, 1998. 121-137 p.

BHABHA, H. O local da cultura. Belo Horizonte: Editora UFMG, 2001. 441 p.

BOURDIEU, P. O poder simbólico. Tradução: de Fernando Tomaz. Rio de Janeiro: Bertrand Brasil, 1989. $311 \mathrm{p}$.

CANCLINI, N. G. Culturas Híbridas. São Paulo: Edusp, 2013. 392 p.

CANDAU, V. M. (org.). Sociedade educação e culturas(S): questões e propostas. 3. Ed., Petrópolis, RJ: Editora Vozes, 2010. 288 p.

DUSSEL, I. O currículo híbrido: domesticação ou pluralização das diferenças? In: LOPES, Alice R. C. e MACEDO, Elizabeth (Orgs.) Currículo: Debates Contemporâneos. São Paulo: Cortez, 2002, 55-77 p.

GOMES, M. A. de O; COLARES, M. L. I. S. A educação em tempos de neoliberalismo: dilemas e possibilidades. Acta Scientiarum. Education, Maringá, v. 34, n. 2, p. 281-290, JulDez, 2012. ISSN: 2178-5198. Disponível em: http://www.redalyc.org/pdf/3033/303325733014.pdf Acesso em: 16 de abr. 2017.

GONÇALVES, L. A; SILVA, P. B. G. O jogo das diferenças, o multiculturalismo e seus conceitos e seus contextos. Belo Horizonte: Autêntica 1998. 120 p.

GRAMSCI, A. Maquiavel, a política e o Estado moderno. Rio de Janeiro: Civilização Brasileira, 1978. 149 p.

HALL, S. A identidade cultural na Pós-modernidade. $5^{\circ}$ ed. Rio de Janeiro: DP\&A, 2001. $102 \mathrm{p}$.

LOPES, A. R. C. e MACEDO, Elizabeth. O pensamento curricular no Brasil. In: LOPES, Alice R. C. e MACEDO, Elizabeth (Orgs.) Currículo: Debates Contemporâneos. São Paulo: Cortez, 2002. 13-54 p.

. A. R.C. Políticas de Currículo: Mediação por Grupos Disciplinares de Ensino de Ciências e Matemática. In: LOPES Alice R. C. e MACEDO, Elizabeth (Orgs.). Currículo de Ciências em debate. Campinas: Papirus, 2004. 45-75 p. 
MANTOAN, M. T. E. Inclusão escolar: o que é? Por quê? Como fazer? 2 ed. São Paulo: Moderna, 2006. 96 p.

McLAREN, P. O Etnógrafo como um Flâneur Pós-Moderno: Reflexividade Crítica e o PósHibridismo como Engajamento Narrativo. In: McLAREN, P. Multiculturalismo Revolucionário: a pedagogia do dissenso para o novo milênio. Porto Alegre: Artes Médicas Sul, 2000. P. 83-117.

MOREIRA, A. F. B; MACEDO, E. Currículo, identidade e diferença. In: MOREIRA, A. F. B., MACEDO, E. (Org.). Currículo, práticas pedagógicas e identidades. Porto, Portugal: Porto Editora, 2002. 15-39 p. Disponível: http://www.scielo.br/pdf/es/v23n79/10847.pdf. Acesso: 15 de abr. 2017.

MOSCOVICI, S. Representações sociais: investigações em Psicologia Social. Petrópolis: vozes, 2010. $404 \mathrm{p}$.

MOURA, M. Diversidade Cultural e Democracia: Breve Reflexão sobre os Desafios da Pluralidade. Textos e Contextos, Salvador, v 3, n 3, p. 29-38, Ago. 2005. ISSN 1673-2441. Disponível: https://issuu.com/flavia.gil/docs/preview-textos_contextos03. Acesso em: 16 abr. 2017.

NEGRI, S. de R. Um currículo democrático na contemporaneidade: desafios e possibilidades teóricas. Educação em Perspectiva, Viçosa, v. 1, n. 2, p. 274-292, jul./dez. 2010. ISSN 21788359. Disponível em:

http://www.seer.ufv.br/seer/educacaoemperspectiva/index.php/ppgeufv/article/viewFile/151/3 9. Acesso em: 16 abr. 2017.

RAYNAUT, C. Pensar no mundo contemporâneo e inovar na produção do conhecimento. $G \& D R$, Taubaté, v. 10, n. 3, p. 4-26, set. 2014. ISSN 1809-239X. Disponível em: http://www.rbgdr.net/revista/index.php/rbgdr/article/view/1469/392. Acesso em: 16 abr. 2017. 